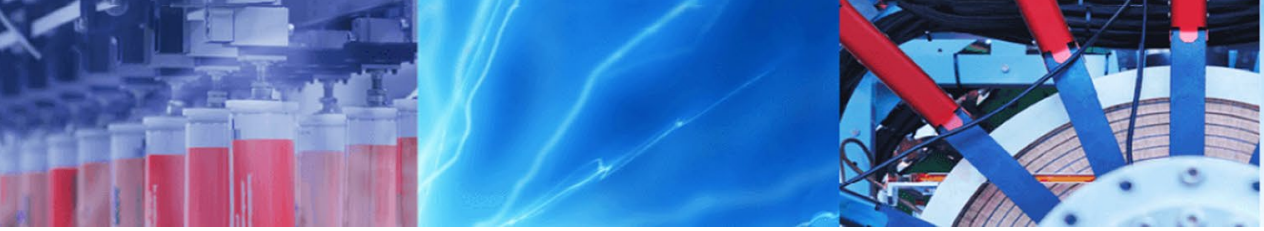

Research Article

\title{
Controlled adsorption and release of amoxicillin in GO/HA composite materials
}

\author{
Othmane Khalifi Taghzouti ${ }^{1,2} \cdot$ Khalil El Mabrouk $^{1} \cdot$ Meriame Bricha $^{1} \cdot$ Khalid Nouneh $^{2}$
}

(c) Springer Nature Switzerland AG 2019

\begin{abstract}
Present work is aimed at preparing hybrid composites based on graphene oxide and hydroxyapatite as a matrix (GO/ $\mathrm{HA}$ ), which can be used as a template for drug delivery after chirurgical operation. Composite materials were synthesized through an in situ precipitation as simple and save-time method. The obtained materials were characterized using infrared spectroscopy (FT-IR), scanning electron microscopy (SEM), thermogravimetric analysis (TGA), and X-ray diffraction (XRD). Hybrid materials were loaded with amoxicillin and the drug delivery during various periods of time was assessed with UV spectroscopy. During loading periods, it was noted that GO has a much larger cumulative drug concentration compared to hydroxyapatite and other composites. Similarly, and during the release process, amoxicillin is released much faster during the earlier stage of immersion before reaching a stationary state towards long periods of time. This variation was found to be dependent on the amount of GO in the HA matrix, as well as on the number of oxygen available on the $\mathrm{GO}$ sheets and the HA surfaces.
\end{abstract}

Keywords Hydroxyapatite · Graphene oxide · Drug delivery · Drug loading · Composites

\section{Introduction}

The bone infection caused by microorganism on orthopaedic surgeries is the costliest complications, and is one of the major increased morbidity in the world [1]. This infection is associated with patient discomfort, longer hospitalization and additional surgeries for the treatment of infected patients [2-5]. Treatment of bone infection at surgical site is actually more demanded to prevent bacterial infections. Traditionally treatment of bone infection is ensured by administration of antibiotic systematically, but unfortunately, the drawbacks of this delivery route is the poor drug diffusion in the blood [6]. However, local delivery of antimicrobial drug on material as carrier, which is able to release the drug needed in the specific organ with a very defined concentration. Therefore, this is a viable solution to ensure a treatment of infection after orthopaedic surgeries [7].
Due to its fascinating properties, graphene has been accompanied by increasing research attention to explore this new material for energy conversion and storage systems $[8,9]$ to photocatalysis [10-13], through drug delivery application. Graphene (Gr), is a single layer at atomic thick, and a two- dimensional (2D) $s p^{2}$ hybridized carbon material arranged in a honeycomb crystal lattice. Graphene had a wide variety of promising biomedical applications such as anti-bacterial paper, cancer targeting, photo-thermal therapy, drug delivery, biological imaging, and tissue engineering $[14,15]$. Graphene has been widely used in his oxidized structure called graphene oxide (GO) due to the abundant hydroxyl, epoxide, and carboxylic groups on the basal plane and edges of graphene oxide surface respectively, which lead to the high dispersion of $\mathrm{GO}$ in water [16]. Consequently, makes their biomedical application in drug loading and delivery possible [17-19]. In addition the large specific surface area $\left(2630 \mathrm{~m}^{2} \mathrm{~g}^{-1}\right)$,

Khalil El Mabrouk, k.elmabrouk@ueuromed.org|'Euromed Research Center, Euromed University of Fes, Eco-Campus, Meknes Road, 30300 Fes, Morocco. ${ }^{2}$ Laboratory of Physics of Condenced Matter (LPMC), Depertement pf Physics, Ibn Tofail University, Kenitra, Morocco.

SN Applied Sciences (2019) 1:226 | https://doi.org/10.1007/s42452-019-0240-y

Received: 20 January 2019 / Accepted: 6 February 2019 / Published online: 12 February 2019 
the good biocompatibility, and high capability of loading drugs through physical adsorption, make $\mathrm{GO}$ an excellent carrier for loading and delivery for a variety of therapeutic drugs, such as doxorubicin, docetaxel, and camptothecin [20-22]. However, controlled drug release rate of GO is essentially very demanded for the performance of drug materials. In fact, if the drug release rate is faster, it can consequently kill some normal cells. In the other hand the drug release rate may not be slow, which can reduce their effective to treat bone infection [23].

Hydroxyapatite $(\mathrm{HA})$ is actually an attractive biomaterial used in hard tissue engineering for restoring damaged bone, owing to its biological properties, and chemical composition similar to natural bone [24]. Also, HA have a great potential as drug delivery system. First and foremost, the geometrical structure of hydroxyapatite was found to have a vital role in adsorption of biomolecules through electrostatic attractions. The crystallographic structure of $\mathrm{HA}$ is formed by two horizontal layer of $\mathrm{PO}_{4}^{3-}$ tetrahedron, located at $z=1 / 4$ and $z=3 / 4$ planes, and positively charged $\mathrm{Ca}^{2+}$ atoms located at $\mathrm{z}=0,1 / 2,1 / 4$ and $3 / 4$ planes and negatively charged $\mathrm{OH}^{-}$located at $1 / 4,3 / 4$ [25]. These two different charges of HA may be responsible for the adsorption of drugs and biomolecules on its surface. In addition, HA is very demanded for its potential application on drug delivery, thanks to the capacity to deliver anti-cancer drug [26], anti-inflammatory drug [27], anti-osteoporotic drug [28]. Therefore, the development of HA-drug systems, e.g. antibiotic, anti-microbial agent, etc., with controlled drug release seems to be an important problem, in view of the infection in bone surgery [29]. It is important to develop more advanced system able to deliver drug when required with optimal dosage within time.

Recently, few research works have introduced hydroxyapatite into graphene oxide in order to combine the advantages properties of GO and hydroxyapatite for drug delivery; and to develop composites with controlled drug release kinetics. For example, $\mathrm{pH}$-sensitive drug carriers have been investigated using $\mathrm{GO} / \mathrm{HA}$ composites and the release rate from these composites was found to be $\mathrm{pH}$-dependent. The drug release in PBS medium (phosphate buffer solution) at a $\mathrm{pH}=4.4$ was found to be higher compared to $\mathrm{pH}=7.4$ and 9 respectively [30]. Furthermore, the porous flower like structure of the $\mathrm{GO}$ / $\mathrm{HA}$ composites revealed a reduction in drug release rate of ibuprofen (IBU), which make this nanocomposite, a promising material for drug delivery application [31]. Also, drug release of a cationic Anticancer doxorubicin was controlled on carbon dots conjugated carboxymethyl cellulose-hydroxyapatite nanocomposite which explained by a diffusion-controlled mechanism [32]. Even more, there is a serious discrepancy about the future application of hydroxyapatite particles, when they are combined with
$\mathrm{GO}$, if the combination will be able to control drug release or not. The big challenge must be achieved is the new composites development functionalized by therapeutic drug to significantly improve local surgical outcomes and reduced bone infection. Despite the progress in graphene based nano-composites, to our knowledge, there are few reports on GO/HA composites as a template for drug delivery to control release drug rate. In this paper, the effect of $\mathrm{GO}$ loading and drugs release will be studied. The drug loading and controlled release will be investigated using Amoxicillin (Fig. 1) as the model drug.

\section{Experimental details}

\subsection{Materials}

Synthetic Graphite (powder, $<20 \mathrm{~mm}$ ), amoxicillin, sulfuric acid $\left(\mathrm{H}_{2} \mathrm{SO}_{4}\right)$, sodium nitrate $\left(\mathrm{NaNO}_{3}\right)$, potassium permanganate $\left(\mathrm{KMnO}_{4}\right)$, hydrogen peroxide $\left(\mathrm{H}_{2} \mathrm{O}_{2}\right)$, chloridric acid $(\mathrm{HCl})$, calcium chloride $\left(\mathrm{CaCl}_{2}\right)$, ammonia water $\left(\mathrm{NH}_{4} \mathrm{OH}\right)$, phosphoric acid $\left(\mathrm{H}_{3} \mathrm{PO}_{4}\right)$ were purchased from Sigma Aldrich Chemicals. All the chemicals were employed without further purification.

\subsection{Apparatus and characterization}

Fourier transform infrared (FTIR) analyses were carried out on a Thermoscientific, IS-50 FT-IR in the frequency range of $4000-400 \mathrm{~cm}^{-1}$ to identify the functional groups of the composites, with a resolution of $4 \mathrm{~cm}^{-1}$. The X-ray diffraction (XRD) patterns of the powders and composites were assayed using an automated $\mathrm{X}$-ray powder diffractometer (XRD, PAnalytical) at a scanning rate of $0.033^{\circ}$ per second in a $2 \theta$ range from $20^{\circ}$ to $80^{\circ}$ with $\mathrm{Cu}$-Ka radiation $(\lambda=1.54,060 \AA)$, operated at $45 \mathrm{kV}$ and $40 \mathrm{~mA}$. Thermogravimetric analysis (TGA) was conducted with TGA Q500. All the samples were carefully grounded to fine powder. The samples were analyzed within the temperature range $25-1000^{\circ} \mathrm{C}$ at a heating rate of $10^{\circ} \mathrm{C} / \mathrm{min}$ under atmospheric environment. The morphology of the hybrids was

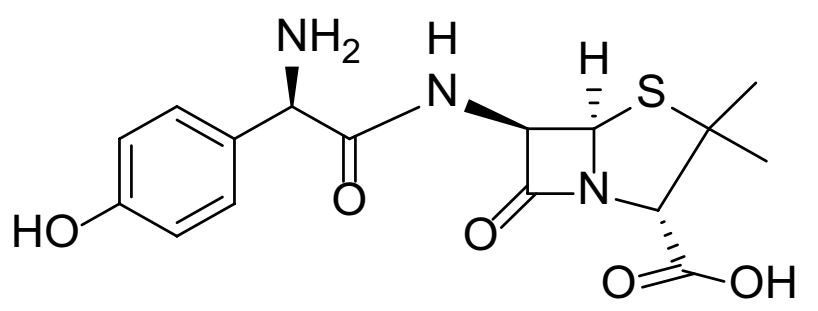

Fig. 1 Chemical structure of Amoxicillin drug molecule 
carried out by using scanning electron microscopy (SEM) on FEI Quanta 200 EDAXR.

\subsection{Synthesis of graphene oxide composites (G0)}

Graphene oxide (GO) was synthesized using Hummer's method from natural graphite. Briefly, $2 \mathrm{~g}$ of graphite powder and $1 \mathrm{~g}$ of $\mathrm{NaNO} 3$ were added to $50 \mathrm{~mL}$ of concentrated $\mathrm{H}_{2} \mathrm{SO}_{4}$ and were stirred in an ice bath, then $6 \mathrm{~g}$ of $\mathrm{KMnO}_{4}$ was slowly added with vigorous stirring. The suspension was kept at $35^{\circ} \mathrm{C}$ for 30 min with stirring. After that, the reaction was heated at $95^{\circ} \mathrm{C}$ and stirred for $30 \mathrm{~min}$ after addition of $180 \mathrm{ml}$ of water. Then, $450 \mathrm{ml}$ of water was slowly added following by the addition of $15 \mathrm{ml}$ $\mathrm{H}_{2} \mathrm{O}_{2}$ (30\%) slowly. The mixture was filtered and washed with $\mathrm{HCl}(1 \mathrm{M}, 37 \%)$ and then with distilled water, until the suspension was neutral and dried at $60^{\circ} \mathrm{C}$ for $24 \mathrm{~h}$ [33].

\subsection{In situ synthesis of HA in graphene oxide suspension}

Predetermined amount of graphene oxide was dispersed by ultra-sonication in $50 \mathrm{ml}$ of water for $2 \mathrm{H}$. Hydroxyapatite was prepared in the presence of $\mathrm{GO}$ solution at different weight fraction of GO by in situ precipitation (Table 1).

$\mathrm{CaCl}_{2}$ precursors $(10.25 \mathrm{mM})$ were dissolved in $50 \mathrm{ml}$ of water and the solution was added drop wise to $\mathrm{GO}$ solution under stirring. After that, $50 \mathrm{ml}$ of diluted $\mathrm{H}_{3} \mathrm{PO}_{4}$ $(6.14 \mathrm{mM})$ was added to the previous solution under agitation during $30 \mathrm{~min}$. The $\mathrm{pH}$ of the solution was then adjusted to 10 by adding ammonia solution $\left(\mathrm{NH}_{4} \mathrm{OH}\right)$. The solution was then stirred for $24 \mathrm{~h}$ at $37^{\circ} \mathrm{C}$. the resulting precipitate was centrifuged and washed four times with distilled water and ethanol. The obtained powder was dried at $80^{\circ} \mathrm{C}$ for overnight.

\subsection{In vitro tests: drug loading, release and biomimetic mineralization}

Loading of amoxicillin (AMX) was carried out by dispersing $\mathrm{GO} / \mathrm{HA}(\mathrm{a}, \mathrm{b}, \mathrm{c}, \mathrm{d}, \mathrm{e})$ in aqueous solution at $\mathrm{pH}=7.42$ at $37^{\circ} \mathrm{C}$ for $24 \mathrm{H}$ in dark environment. The liquid supernatant

Table 1 Samples acronyms of the prepared nanocomposites was separated from solid samples using centrifugation operating at $10000 \mathrm{rpm}$ for $5 \mathrm{~min}$. The drug loading was calculated according to the Eq. (3). The release of AMX from various composite samples (GO/HA) was carried out by dispersing pre-weighed samples in PBS medium at $\mathrm{pH}=7.42, \mathrm{~T}=37^{\circ} \mathrm{C}$ (in an incubator) at various period of times $(1,2,4.5,5.5,24,48,72$ and $96 \mathrm{H})$. Periodically, $4 \mathrm{ml}$ of dissolution medium were collected and replaced by the same volume. The PBS solutions were analysed at $272 \mathrm{~nm}$ by UV/VIS Spectrometer Lamda-850. The experiments (loading and release) were repeated in triplicate to get mean and the standard deviation. The amount of the $A M X$ released was calculated using a linear regression. The cumulative release of $A M X$ was calculated from Eq. (2):

Drug loading $(\%)=\frac{m_{0}-m_{t}}{m_{0}} \times 100$

Cumulative drug release $(\%)_{t}$

$$
=\left(\frac{\mathrm{m}_{t}}{\mathrm{~m}_{0}} \times 100\right)_{t}+(\% \text { drug release })_{t-1}
$$

$\mathrm{m}_{0}$ is the initial mass of drug used in loading $(1 \mathrm{mg} / \mathrm{ml}), \mathrm{m}_{\mathrm{t}}$ is the mass of AMX collected in aqueous or PBS solution, $t$ is the time of collection.

To investigate the apatite forming ability, cylindrical shaped samples weighing $0.1 \mathrm{~g}$ prepared by uniaxial press were soaked in $30 \mathrm{~mL}$ of SBF [34] solution in a polyethylene plastic container and were placed in an incubator at $37^{\circ} \mathrm{C}\left( \pm 0.5^{\circ} \mathrm{C}\right)$. After 21 days of immersion, the samples were collected from the SBF solution, rinsed with water and dried at room temperature. SEM observation was used to check the apatite formation on the surfaces of cylindrical shaped samples.

\section{Results and discussion}

\subsection{Preparation and characterization of GO/HA composites}

Scheme 1 illustrates the synthesis process of the composites GO/HA (a, b, c, d, and e). The hybrid materials were prepared using in situ precipitation method. First, GO was ultrasonically well dispersed in water. Then, in situ precipitation of HA was achieved. During the reaction process, polar functional groups of GO surface act as nucleation and growth sites of HA. First, calcium ions $\left(\mathrm{Ca}^{2+}\right)$ with positive charge was strongly attracted to $\mathrm{GO}$ surfaces via electrostatic interaction. Then, phosphate ions $\left(\mathrm{PO}_{4}^{3-}\right)$ will counterbalance the electronic charge of the surface. The increase of the $\mathrm{pH}$ of the solution to 
Scheme 1 The experimental process of synthesized composites

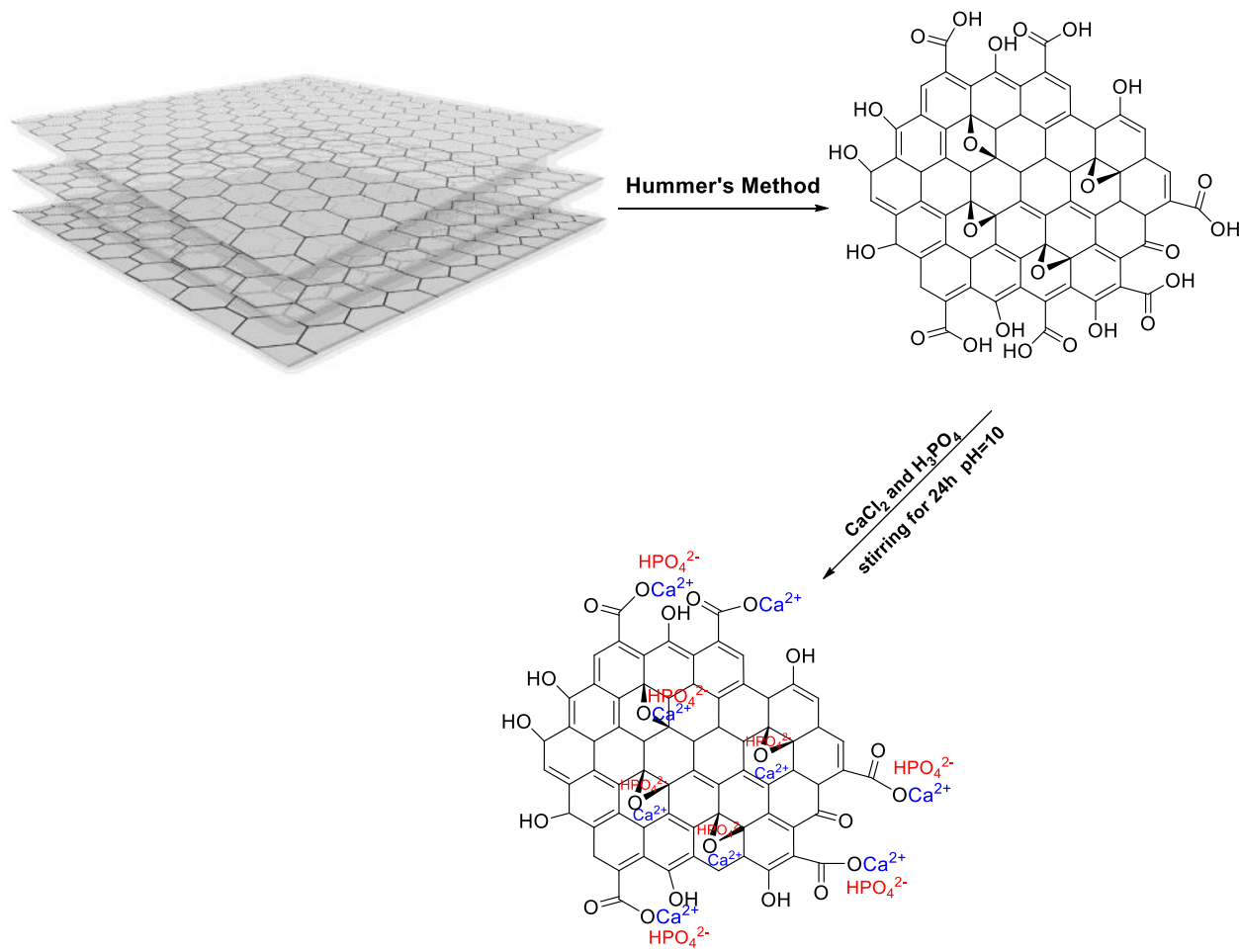

10-10.5, will spontaneously induced nucleation and growth of HA on GO surfaces within time.

\subsection{FTIR and UV analysis of GO and GO/HA composites}

FTIR spectra of GO and GO/HA (a, b, c, d, e) composites are displayed in Fig. 2. According to Fig. 2a, the absorbance bands at $3203 \mathrm{~cm}^{-1}$ and $1246 \mathrm{~cm}^{-1}$ were assigned to the hydroxyl groups $(\mathrm{O}-\mathrm{H}), 1620 \mathrm{~cm}^{-1}$ to the $s p^{2}$ hybridized $\mathrm{C}=\mathrm{C}$ vibration stretching. Besides, the adsorption peaks produced by other functional groups such as carboxyl $C=O\left(1730 \mathrm{~cm}^{-1}\right)$, epoxy $C-O\left(1051 \mathrm{~cm}^{-1}\right)$ groups on the surface of GO [35]. After nucleation and growth of HA particles, the future composites were examined with FTIR. Infrared spectra of GO/HA composites showed all characteristic peaks of hydroxyapatite at 560,600,967 and $3345 \mathrm{~cm}^{-1}$ respectively (Fig. 2b) [36]. Moreover, according Fig. 2b, it was observed a net reduction of pic intensity of the absorption band of $C=0$ $\left(1730 \mathrm{~cm}^{-1}\right)$ indicating a strong interaction between $\mathrm{HA}$ and GO nanosheets. It was also observed from UV-vis spectra of GO and GO/HA composite (Fig. 2d) that GO nanosheets consist of the band at $232 \mathrm{~nm}$, which is characteristic of $\pi-\pi^{*}$ transitions of carboxyl group $(C=0)$ [37]. After addition of $\mathrm{HA}$, the peak located at $232 \mathrm{~nm}$ was shifted to $310 \mathrm{~nm}$, which confirmed the strong interaction between $\mathrm{HA}$ and $\mathrm{GO}[31,38]$.

\subsection{X-ray diffraction studies and thermogravimetric analysis}

Phase and crystallinity of prepared composites were identified using XRD analysis. Figure 3a shows the XRD pattern of graphite and graphene oxide where graphite shows an intense peak at $2 \theta=26.5^{\circ}$ and $G O$ at $2 \theta=10.1^{\circ}$ (due to (002) plane) which clearly indicates the oxidation of graphite affecting its crystal structure and the interlayer spacing which has increased from 3.4 to $8.7 \AA$ [35]. Figure $3 \mathrm{~b}$ displayed the XRD patterns of the GO/HA composites and $\mathrm{HA}$ powders. All samples presented diffraction peaks of HA crystal at $2 \theta$ of $25.79,31.9,39.3,46.36,49.5$, 53.26 corresponding to (002), (211), (310), (222), (313), (004) inter-reticular plans [39]. These characteristic peaks are consistent with the standard diffraction pattern of $\mathrm{HA}$ (JCPDF 00-001-1008). However, after formation of HA on $\mathrm{GO}$ sheets, the (002) plan of $\mathrm{GO}$ was not observed in the composites, due the lower amount of $\mathrm{GO}$, which was consistent with previous studies [40].

TGA analysis were further performed to confirm the weight change of GO, HA, and GO/HA (a, b, c, d, e) (Fig. 4). The samples were heated from room temperature to $1000^{\circ} \mathrm{C}$ at a rate of $10^{\circ} \mathrm{C} / \mathrm{min}$. The initial weight loss at around $100^{\circ} \mathrm{C}$ was attributed to the evaporation of water for all samples. According to this figure, the GO is thermally unstable and recorded two significant loss weight for at around $200^{\circ} \mathrm{C}$ and $510^{\circ} \mathrm{C}$ due to decomposition of oxygenated functional groups. The former are attributed 

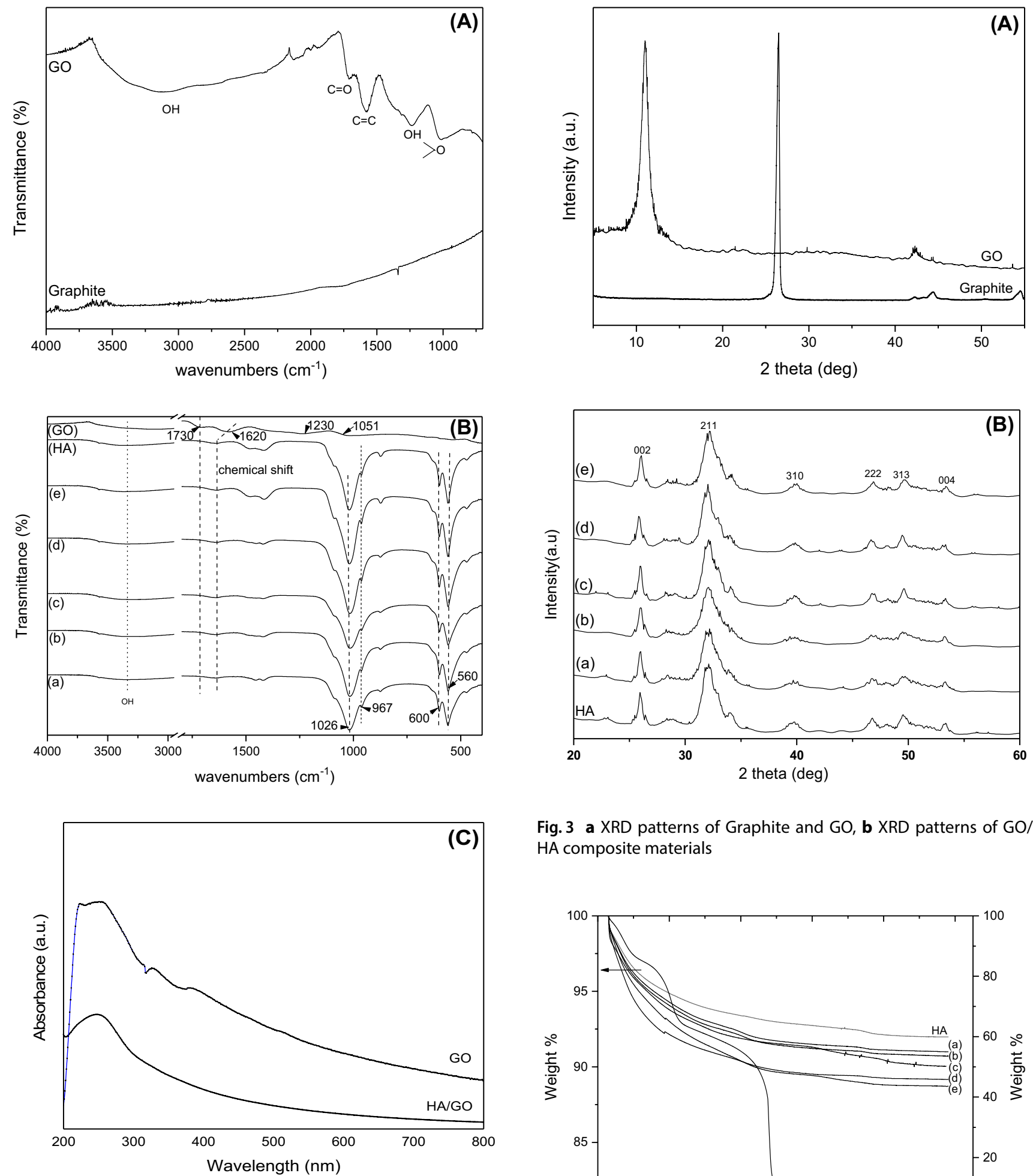

Fig. 2 FTIR spectra of a graphite and graphene oxide, $\mathbf{b}$ GO/HA corresponding composites and $\mathbf{c}$ UV-vis spectra of graphene oxide (GO) and selected GO/HA composite

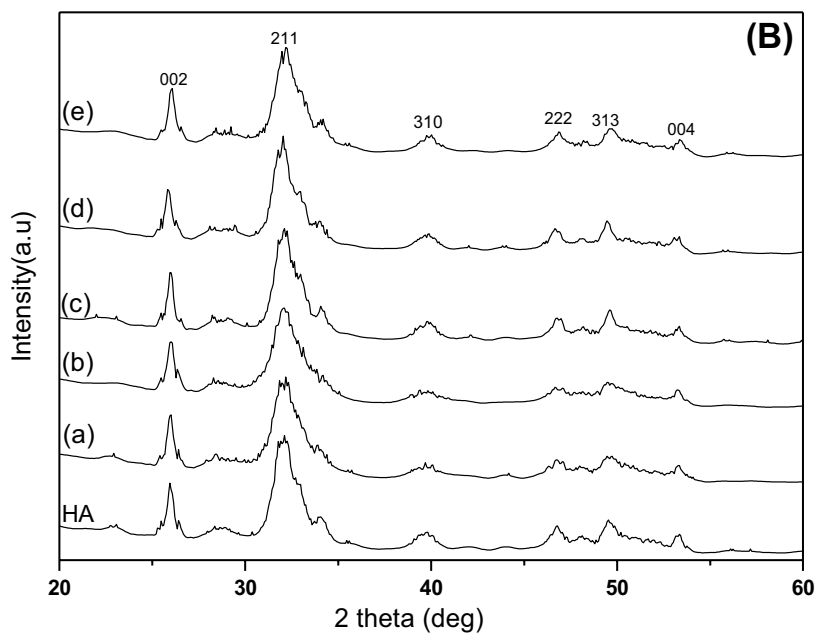

Fig. 3 a XRD patterns of Graphite and GO, b XRD patterns of GO/ HA composite materials

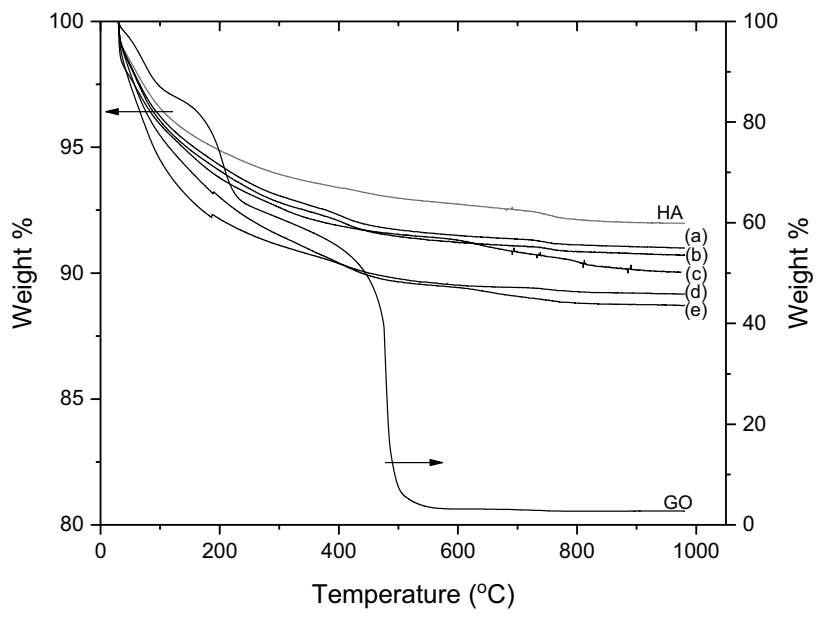

Fig. 4 TGA profiles of HA, GO and GO composite 
to formation of $\mathrm{CO}$, and $\mathrm{CO}_{2}$, and the latter are attributed to the combustion of the carbon of GO [41]. The weight loss of $\mathrm{GO}$ at $200^{\circ} \mathrm{C}$ was $20 \mathrm{wt} \%$, compared to GO/HA (a) to $\mathrm{GO} / \mathrm{HA}$ (e) that show a variation of weight loss from 2.5 to $4.5 \mathrm{wt} \%$ respectively. In addition, when the temperature reached $900{ }^{\circ} \mathrm{C}$, no significant weight loss was recorded for $\mathrm{HA}$, and GO/HA composites ( $a, b, c$, d, and e), which due to their high thermal stability of HA. The final weight loss was also found to be GO dependent. the higher the graphene loading rate in composite materials, the more a net decrease in mass loss is recorded at $900^{\circ} \mathrm{C}$.

\subsection{AMX loading and in vitro drug release}

According to FTIR spectra of AMX (Fig. 5), the absorbance bands at $1770 \mathrm{~cm}^{-1}, 1640-1560 \mathrm{~cm}^{-1}, 1350-1280 \mathrm{~cm}^{-1}$, $3650-3590 \mathrm{~cm}^{-1}$ were corresponded to ketone, primary amine, secondary amine, and hydroxyl (broad) groups of amoxicillin respectively [42]. The characteristic bands of AMX were also observed for all composite materials (GO/ $\mathrm{HA}$ ) which confirmed the successful loading of AMX drug molecule in all samples. As mentioned above, the UV-Vis spectroscopy displayed a characteristic absorbance band at $272 \mathrm{~nm}$ for amoxicillin (Fig. 2c). The loading content in composite materials were assessed by UV spectroscopy and for that the calibration curve for various concentration of AMX was released.

Figure 6a shows the evolution of the concentration of $A M X$ in GO, HA and their corresponding composites. With respect to this figure, it can be observed that virgin graphene exhibited the highest absorbance of the AMX drug molecules (82.19\%) compared to HA $(51.99 \%)$ and the other composites. This can be explained by the abundance

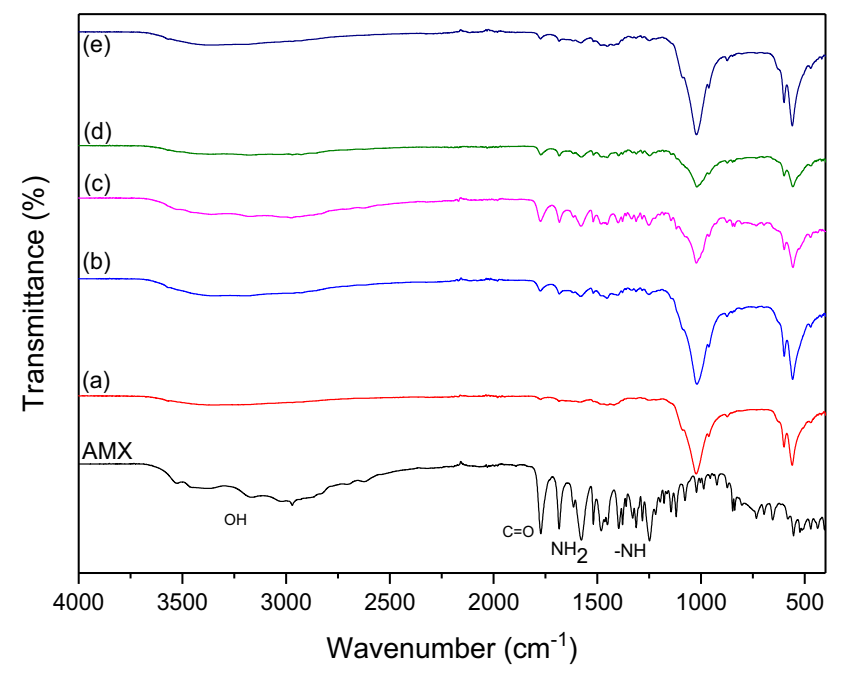

Fig. 5 FTIR spectra of GO/HA composite samples loaded with AMX drug molecule
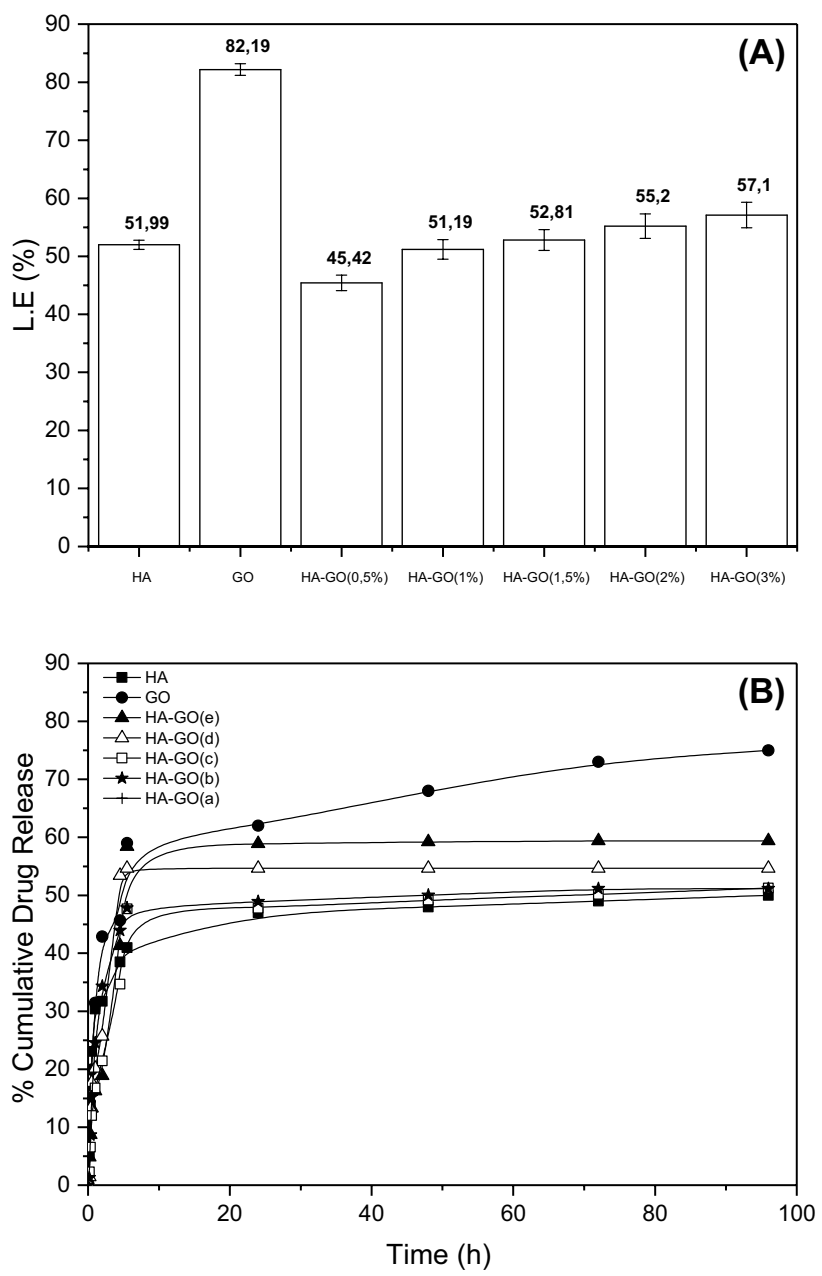

Fig. 6 AMX loading (a) and release (b) profiles from HA, GO and $\mathrm{GO} / \mathrm{HA}$ carriers

of the graphene-sheets by functional groups capable of developing favourable interactions ( $\pi-\pi$ interactions) with AMX such as carboxyl, epoxide and carboxylic acid [43]. The second parameter impacting this extraordinary absorbance of the AMX drug molecules is the higher specific surface area of graphene sheets.

In the case of $\mathrm{HA}$, the average cumulative concentration of the AMX absorbed on the surface of the granules reached $51.99 \%$. This modest value compared to that obtained in the case of the GO, is explained by the methodology adopted during synthetizing the HA. It should be noted that the preparation of the HA by the precipitation method with vigorous stirring does not adequately allowed a good control of the geometry of the grains, neither it can increase the specific surface area of the apatite particles such as the case observed whit surfactant assisted particle synthesis of hydroxyapatite [29]. This will effectively reduce the exposure of functional groups able of developing favourable interactions with AMX. 
For the intermediate phases, it has been observed that the cumulative concentration of AMX increased with GO addition in the prepared composites. In the case of $\mathrm{GO} /$ HA composites ( $a, 0.5 w t \%$ of graphene), a value of $45.42 \%$ was recorded. This value is slightly lower to that observed in the case of the virgin HA and can be explained by a net reduction of the oxygenated sites necessary to interact with the AMX drug molecules. Generally, during the formation of hydroxyapatite in the presence of suspended graphene sheets, the formation of covalent bonds between HA and GO has been observed and may be responsible for this decrease. This has been also confirmed by the FTIR spectra (Fig. 2b). As the amount of GO increased in the prepared composites, the cumulative concentration of $A M X$ increase to reach its higher value in the case of $3 \mathrm{wt} \%$ of GO addition. The available of both functional groups on nanosheets of $\mathrm{GO}$ and $\mathrm{HA}$ are responsible of this enhancement. In addition, it was reported earlier that the percentage of graphene filled HA should not exceed $5 \mathrm{wt} \%$ to not deteriorate biological cells [44-46].

Figure $6 \mathrm{~b}$ shows the kinetics of release of AMX drug molecules in PBS medium for virgin materials ( $\mathrm{HA}$ and $\mathrm{GO}$ ) and their corresponding composites. According to this figure, it can be seen that the drug release is graphene oxide dependent. As a function of time, all composites presented a net increase in the AMX concentration in the PBS solution during the earlier stage of immersion (for periods of time less than $5 \mathrm{~h}$ ) before reaching a quasi-stationary states after $5 \mathrm{~h}$ of immersion. The steady states are therefore dependent on the amount of graphene in composite materials. As the rate of graphene oxide was increased in the composite materials, as the concentration limit of AMX in the PBS solution become more important. Graphene oxide therefore has the highest concentration while HA has the lowest one. This phenomenon is explained by the amount of AMX absorbed on the surface of composites during drug loading as well as by the strength of the concentration gradient during the release in the PBS solution. The rapid delivery of the drug during the earlier stage is required immediately after surgery for the effective inhibition of microorganisms and then a controlled release is needed to aid long-time healing and to avoid the toxic and adverse systemic effect caused by high concentration of antibiotics administrated orally.

In order to qualify the mechanism of AMX release, several researchers suppose that drug release mechanism occurred by either drug diffusion or eroding of the matrix, which influenced the rate of release. Several models have been used to explain the mechanisms governing the drug release. Semiempirical models were developed by Ritger \& Peppas (Eq. 3) [47] and kopcha (Eq. 4) [48-50].

$\frac{M_{t}}{M_{\infty}}=k t^{n}$
$M_{t}=A \sqrt{t}+B t$

$\frac{M_{t}}{M_{\infty}}$ is the fractional solute release, $M t$ is the amount of released drug at time $t, M_{\infty}$ is total amount of released drug, $\mathrm{k}$ is a constant, and $\mathrm{n}$ is the diffusional exponent characteristic of the release mechanism. $n$ gives an information of the drug-release mechanism: if $n<0.5$, the mechanism corresponded to Fickian diffusion and if $n$ is situated between 0.5 and 1.0, the mechanism will correspond to non-Fickian transport. For Eq. 4, $A$ is a diffusional term and $B$ is the erosion term. When $A / B>1$, the diffusion phenomenon is predominant, and when $A / B<1$ the erosion phenomenon is predominant. Table 2 represents the results of calculations of parameters $n, A$ and $B$ respectively. According to the calculated parameters, it can be concluded from both models, that the drug release followed the Fickian diffusion law for all samples.

\subsection{Biomimetic mineralization}

Two factors are consistent from the point of view of good implants grafting: good osseointegration of the biomaterials with surrounding tissues and excellent biocompatibility of the biomaterials for the growth promotion of osteoblast cells [51]. A strong bone-bonding ability between the implant and the surrounding tissues is generally due to a regular distribution and fast apatite formation. In this study, we used in vitro acellular bioactivity tests using simulated body fluid (SBF) as a standard precursor medium mimicking the biomineralization process of the new bone. In order to evaluate this capacity, GO/HA composite materials were immersed in SBF for different periods of time (1-21 days). All GO/HA composite samples showed the formation of a new apatite layers as consistently confirmed by SEM and FTIR results. Figure 7 displayed the representative surface morphologies obtained from SEM of pure HA and the GO/HA composites after being soaked in SBF for 21 days.

Table 2 Parameters of the AMX release profile fitting according to Ritger and Peppas and Korsmeyer models

\begin{tabular}{lll}
\hline Samples & $\begin{array}{l}\text { Korsmeyer-Peppas } \\
\mathrm{n}\end{array}$ & $\begin{array}{l}\text { Kopcha } \\
\mathrm{A} / \mathrm{B}\end{array}$ \\
\hline $\mathrm{HA}$ & 0.39 & $\gg 1$ \\
GO & 0.38 & $\gg 1$ \\
GO/HA (a) & 0.45 & $\gg 1$ \\
GO/HA (b) & 0.46 & $\gg 1$ \\
GO/HA (c) & 0.49 & $\gg 1$ \\
GO/HA (d) & 0.46 & $\gg 1$ \\
GO/HA (e) & 0.34 & $\gg 1$ \\
\hline
\end{tabular}




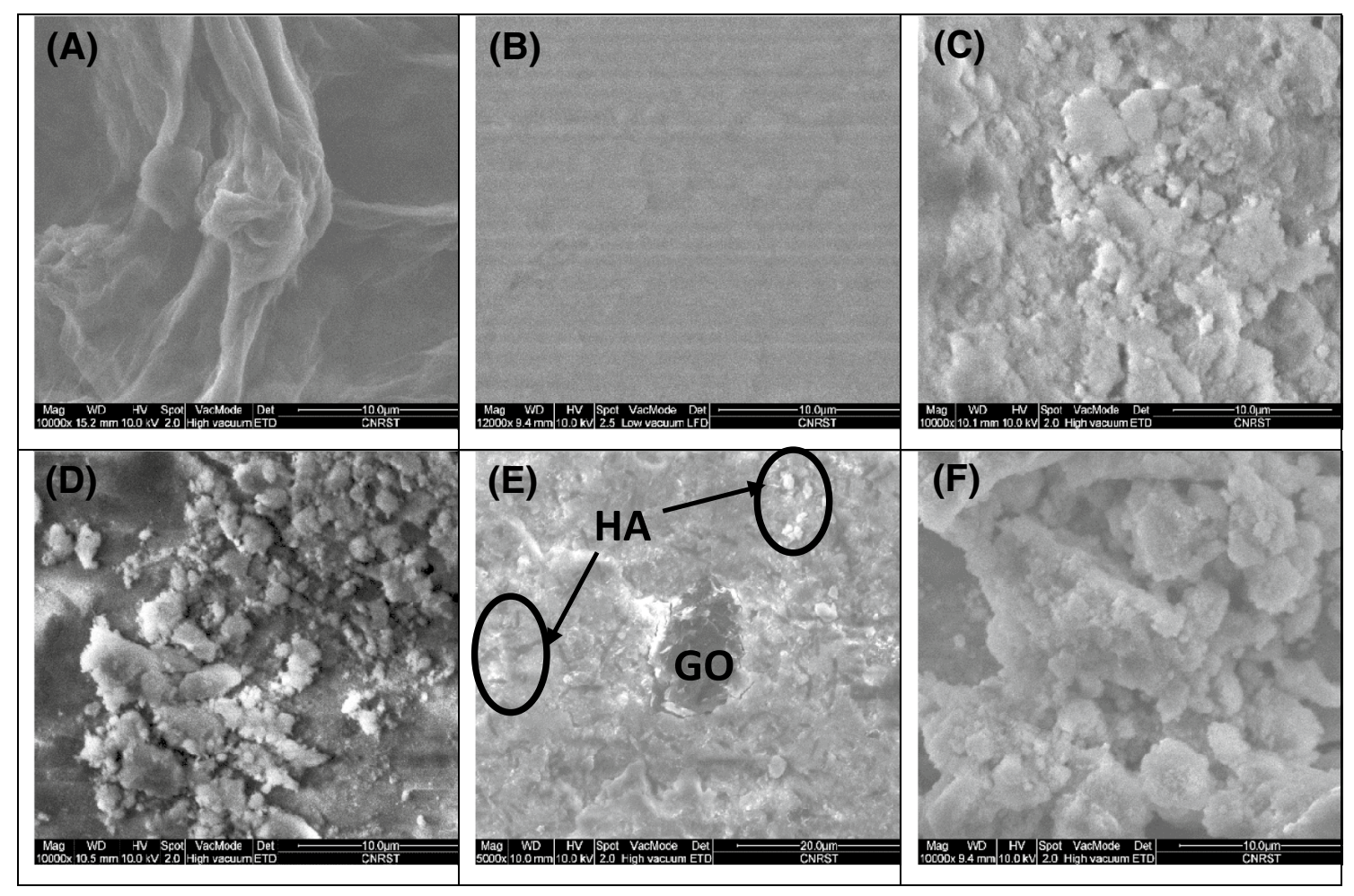

Fig. 7 SEM micrographs of a GO sheets, b HA before soaking, $\mathbf{c} H A, \mathbf{d ~ G O} / \mathrm{HA}(0.5 \%)$, e GO/HA (2\%), f GO/HA (3\%) after 21 days of soaking in SBF medium

Figure 7a revealed that GO appears like folded flakes, multi layered and wavy, these observations are consistent with those from Mohandes et al. [52] study. However, $\mathrm{HA}$ pellet displayed a smooth surface before soaking in SBF medium (Fig. 7b). In contrary, it's clearly observed that the morphology of mineralization product varies with the addition of GO into the HA matrix and varied from spherical to sheet-like apatite forms. Increasing the amount of $\mathrm{GO}$ in the composites promote the deposition of a dense layer of spherical-like apatite, although pure HA ceramics showed a platelet-like crystals with the typical HA morphology. In addition, it is observed some microcraks on the GO containing samples, indicating the formation of a thick deposit [53]. The apatite layer deposition is controlled by the presence of available oxygen functionalities on GO and HA surfaces. Thereafter, both of them proceed as competing nucleation points for ionic cluster precursors. For pure HA, the same situation is observed in the case of the formation of apatite on the surface of sintered ceramics after soaking in SBF, which allows for selective ion diffusion [54-56].

In the case of GO/HA composite materials, the formation of apatite layer after 21 days of immersion (Fig. 7d-f). They specifically grow on the HA particles, and interestingly, few of them appear on divers functional groups present on $\mathrm{GO}$ nanosheets, which remain accessible after the in situ synthesis of hydroxyapatite. These observations suggested that HA nuclei forming on the GO/HA surface retain a high reactivity which allows them to migrate towards the $\mathrm{GO} / \mathrm{HA}$ surface to initiate HA growth and resulted on a dense apatite layer. All the observations showed clearly that the presence of hydroxyapatite and GO nanosheets are recommended to obtain a rough surface after the deposition of the new apatite layers.

As known, that this rough surface is ideal for the better adhesion of cells [57]. The formation of apatite particles on the various hybrid composites surfaces is followed more closely by FTIR spectroscopy (Fig. 8). After incubation for 21 days, the FTIR pattern revealed the presence of $\mathrm{PO}_{4}^{3-}$ and $\mathrm{OH}$ groups. Weak $\mathrm{PO}_{4}^{3-}$ bands appeared for $\mathrm{HA}$ samples. After further addition of $\mathrm{GO}$, strong $\mathrm{PO}_{4}^{3-}$ bands were observed. Among these bands, the band at $964 \mathrm{~cm}^{-1}$ is due to the symmetric stretching mode $v 1\left(\mathrm{PO}_{4}^{3-}\right), 1015$ and $1089 \mathrm{~cm}^{-1}$ to the vibration mode $v 3\left(\mathrm{PO}_{4}^{3-}\right), 597,560 \mathrm{~cm}^{-1}$ and $472 \mathrm{~cm}^{-1}$ to bending modes $\mathrm{V} 4\left(\mathrm{PO}_{4}^{3-}\right)$. Then, the FTIR results also confirmed the formation of apatite phase on the GO/HA composites surfaces after soaking in SBF medium $[36,58]$. The most significant and interesting finding is that hydroxyapatite and graphene oxide are a promising combination for bone implant applications [57]. 


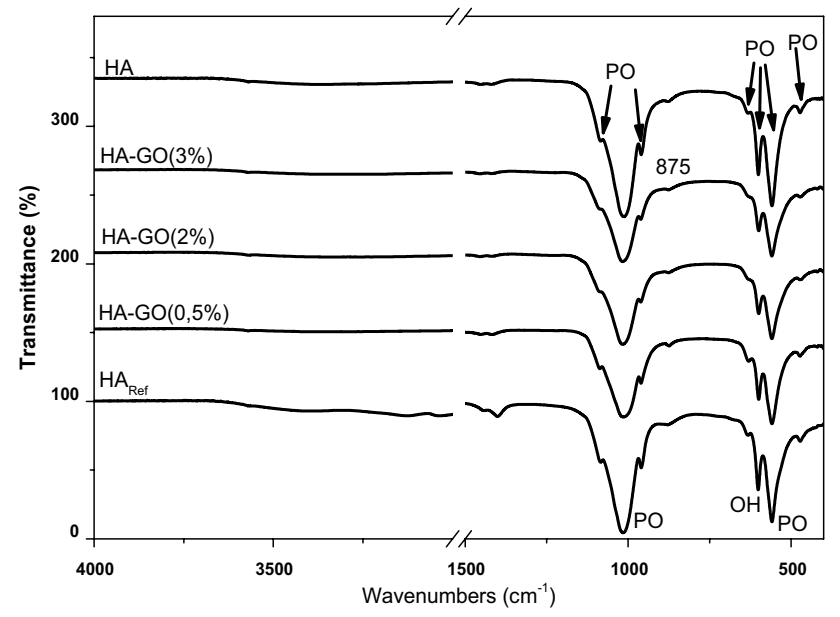

Fig. 8 FTIR spectra of the pure $\mathrm{HA}$ as reference, and pure $\mathrm{HA}, \mathrm{GO}$ / $\mathrm{HA}(\mathrm{a}, \mathrm{d}, \mathrm{e})$ after 21 days of soaking in SBF medium

\section{Conclusions}

To summarize, composite materials based on hydroxyapatite and graphene oxide were synthetized through in situ precipitation as simple and save-time method. Hybrid materials were loaded with amoxicillin as drug molecule and drug release was assessed by UV-Vis spectroscopy. In addition, the drug release was found to be GO dependent and the kinetics of drug release had a tendency to fit well with Fickian diffusion model. Moreover, the composite materials sustained the release of phosphate and calcium ions in SBF, which synergistically assists the ECM (Extracellular matrix) ossification and promotes new bone regeneration. Furthermore, the GO contentment was found to accelerate the process of biomineralization and promoted new bone formation.

Acknowledgements The Authors are grateful to the financial support allowable from Euromed University of Fes - Morocco and National Center for Scientific and Technical Research - Morocco, PPR2 Programme.

\section{Compliance with ethical standards}

Conflict of interest The authors declare that they have no conflict of interest.

\section{References}

1. Noukrati H, Cazalbou S, Demnati I et al (2016) Injectability, microstructure and release properties of sodium fusidateloaded apatitic cement as a local drug-delivery system. Mater Sci Eng C 59:177-184. https://doi.org/10.1016/j. msec.2015.09.070
2. Green JW, Wenzel RP (1977) Postoperative wound infection: a controlled study of the increased duration of hospital stay and direct cost of hospitalization. Ann Surg 185:264-268. https:// doi.org/10.1097/00000658-197703000-00002

3. Kluytmans JAJW, Mouton JW, Maat APWM et al (1994) Surveillance of postoperative infections in thoracic surgery. J Hosp Infect 27:139-147. https://doi.org/10.1016/0195-6701(94)90007 $-8$

4. Kluytmans J, Mouton JW, ljzerman EPF et al (1995) Nasal carriage of Staphylococcus aureus as a major risk factor for wound infections after cardiac surgery. J Infect Dis 171:216-219

5. Coellot R, Glenister H, Fererest J et al (1993) The cost of infection in surgical patients: a case-control study. J Hosp Infect $25: 239-250$

6. Dubnika A, Loca D, Rudovica V et al (2017) Functionalized silver doped hydroxyapatite scaffolds for controlled simultaneous silver ion and drug delivery. Ceram Int 43:3698-3705. https:// doi.org/10.1016/j.ceramint.2016.11.214

7. Reina G, González-Domínguez JM, Criado A et al (2017) Promises, facts and challenges for graphene in biomedical applications. Chem Soc Rev 46:4400-4416. https://doi.org/10.1039/ c7cs00363c

8. Hughes G, Trigg J (2009) Remembering the charge of the light brigade: its commemoration, war memorials and memory. Bastions Barbed Wire Stud Archaeol Confl. https://doi.org/10.1002/ anie. 201806221

9. Quan Q, Lin X, Zhang N, Xu YJ (2017) Graphene and its derivatives as versatile templates for materials synthesis and functional applications. Nanoscale 9:2398-2416. https://doi. org/10.1039/c6nr09439b

10. Lu KQ, Xin X, Zhang N et al (2018) Photoredox catalysis over graphene aerogel-supported composites. J Mater Chem A 6:4590-4604. https://doi.org/10.1039/c8ta00728d

11. Zhang $N$, Yang $M Q$, Liu S et al (2015) Waltzing with the versatile platform of graphene to synthesize composite photocatalysts. Chem Rev 115:10307-10377. https://doi.org/10.1021/acs.chemr ev.5b00267

12. Han C, Zhang N, Xu YJ (2016) Structural diversity of graphene materials and their multifarious roles in heterogeneous photocatalysis. Nano Today 11:351-372. https://doi.org/10.1016/j. nantod.2016.05.008

13. Yang $M Q$, Zhang N, Pagliaro M, Xu YJ (2014) Artificial photosynthesis over graphene-semiconductor composites. Are we getting better? Chem Soc Rev 43:8240-8254. https://doi. org/10.1039/c4cs00213j

14. Zhang Y, Nayak TR, Hong H, Cai W (2012) Graphene: a versatile nanoplatform for biomedical applications. Nanoscale 4:38333842. https://doi.org/10.1039/c2nr31040f

15. Wu X, Zheng S, Ye Y et al (2018) Enhanced osteogenic differentiation and bone regeneration of poly(lactic-: $\mathrm{Co}$-glycolic acid) by graphene via activation of PI3K/Akt/GSK-3 $\beta / \beta$-catenin signal circuit. Biomater Sci 6:1147-1158. https://doi.org/10.1039/ c8bm00127h

16. Depan D, Pesacreta TC, Misra RDK (2014) The synergistic effect of a hybrid graphene oxide-chitosan system and biomimetic mineralization on osteoblast functions. Biomater Sci 2:264-274. https://doi.org/10.1039/c3bm60192g

17. Sun X, Liu Z, Welsher K et al (2008) Nano-graphene oxide for cellular imaging and drug delivery. Nano Res 1:203-212. https ://doi.org/10.1007/s12274-008-8021-8

18. Liu Z, Robinson JT, Sun X, Dai H (2008) PEGylated nano-graphene oxide for delivery of water insoluble cancer drugs (b). J Am Chem Soc 130:10876-10877. https://doi.org/10.1021/ja803 $688 \mathrm{x}$

19. Yang X, Zhang X, Ma Y et al (2009) Superparamagnetic graphene oxide-Fe3O4 nanoparticles hybrid for controlled 
targeted drug carriers. J Mater Chem 19:2710. https://doi. org/10.1039/b821416f

20. Zhao X, Liu P (2014) Biocompatible graphene oxide as a folate receptor-targeting drug delivery system for the controlled release of anti-cancer drugs. RSC Adv 4:24232-24239. https ://doi.org/10.1039/C4RA02466D

21. Liu J, Cui L, Losic D (2013) Graphene and graphene oxide as new nanocarriers for drug delivery applications. Acta Biomater 9:9243-9257. https://doi.org/10.1016/j.actbio.2013.08.016

22. Yang Y, Wang Y, Zhu M et al (2017) RGO/AuNR/HA-5FU nanocomposite with multi-stage release behavior and efficient antitumor activity for synergistic therapy. Biomater Sci 5:9901000. https://doi.org/10.1039/c7bm00007c

23. Wang $H$, Sun D, Zhao N et al (2014) Thermo-sensitive graphene oxide-polymer nanoparticle hybrids: synthesis, characterization, biocompatibility and drug delivery. J Mater Chem B 2:1362-1370. https://doi.org/10.1039/c3tb21538e

24. Rasouli R, Barhoum A, Uludag H (2018) A review of nanostructured surfaces and materials for dental implants: surface coating, patterning and functionalization for improved performance. Biomater Sci 6:1312-1338. https://doi.org/10.1039/ $\mathrm{c} 8 \mathrm{bm} 00021 \mathrm{~b}$

25. Cazalbou S, Combes C, Eichert D, Rey C (2004) Adaptative physico-chemistry of bio-related calcium phosphates. J Mater Chem 14:2148-2153

26. Xiong H, Du S, Ni J et al (2016) Mitochondria and nuclei dualtargeted heterogeneous hydroxyapatite nanoparticles for enhancing therapeutic efficacy of doxorubicin. Biomaterials 94:70-83. https://doi.org/10.1016/j.biomaterials.2016.04.004

27. Öner M, Yetiz E, Ay E, Uysal U (2011) Ibuprofen release from porous hydroxyapatite tablets. Ceram Int 37:2117-2125. https ://doi.org/10.1016/j.ceramint.2011.02.021

28. Seshima H, Yoshinari M, Takemoto $S$ et al (2006) Control of bisphosphonate release using hydroxyapatite granules. J Biomed Mater Res Part B Appl Biomater 78B:215-221. https ://doi.org/10.1002/jbm.b.30446

29. Komlev VS, Barinov SM, Koplik EV (2002) A method to fabricate porous spherical hydroxyapatite granules intended for timecontrolled drug release. Biomaterials 23:3449-3454. https:// doi.org/10.1016/S0142-9612(02)00049-2

30. Bharath G, Latha BS, Alsharaeh EH et al (2017) Enhanced hydroxyapatite nanorods formation on graphene oxide nanocomposite as a potential candidate for protein adsorption, $\mathrm{pH}$ controlled release and an effective drug delivery platform for cancer therapy. Anal Methods 9:240-252. https://doi. org/10.1039/c6ay02348g

31. Yao C, Zhu J, Xie A et al (2017) Graphene oxide and creatine phosphate disodium dual template-directed synthesis of $\mathrm{GO} /$ hydroxyapatite and its application in drug delivery. Mater Sci Eng C 73:709-715. https://doi.org/10.1016/j.msec.2016.11.083

32. Sarkar C, Chowdhuri AR, Kumar A et al (2018) One pot synthesis of carbon dots decorated carboxymethyl cellulosehydroxyapatite nanocomposite for drug delivery, tissue engineering and Fe3 + ion sensing. Carbohydr Polym 181:710-718. https://doi.org/10.1016/j.carbpol.2017.11.091

33. Núñez JD, Benito AM, González R, Aragón A, Arenal R, Maser WK (2014) Integration and bioactivity of hydroxyapatite grown on carbon nanotubes and graphene oxide. Carbon 79:590-604

34. Kokubo T, Takadama $\mathrm{H}$ (2006) How useful is SBF in predicting in vivo bone bioactivity? Biomaterials 27:2907-2915. https:// doi.org/10.1016/j.biomaterials.2006.01.017

35. Li M, Wang Y, Liu Q et al (2013) In situ synthesis and biocompatibility of nano hydroxyapatite on pristine and chitosan functionalized graphene oxide. J Mater Chem B 1:475-484. https://doi.org/10.1039/c2tb00053a
36. Zeng Y, Pei X, Yang S et al (2016) Graphene oxide/hydroxyapatite composite coatings fabricated by electrochemical deposition. Surf Coat Technol 286:72-79. https://doi.org/10.1016/j.surfc oat.2015.12.013

37. Zhang J, Yang H, Shen $\mathrm{G}$ et al (2010) Reduction of graphene oxide via $<\mathrm{scp}>\mathrm{I}</ \mathrm{scp}>$-ascorbic acid. Chem Commun 46:1112-1114. https://doi.org/10.1039/B917705A

38. Shen J, Shi M, Yan B et al (2010) Covalent attaching protein to graphene oxide via diimide-activated amidation. Colloids Surf B Biointerfaces 81:434-438. https://doi.org/10.1016/j.colsu rfb.2010.07.035

39. Butun S, Ince FG, Erdugan H, Sahiner N (2011) One-step fabrication of biocompatible carboxymethyl cellulose polymeric particles for drug delivery systems. Carbohydr Polym 86:636-643. https://doi.org/10.1016/j.carbpol.2011.05.001

40. Liu H, Xi P, Xie G et al (2012) Simultaneous reduction and surface functionalization of graphene oxide for hydroxyapatite mineralization. J Phys Chem C. https://doi.org/10.1021/jp2102226

41. Bissessur R, Liu PKY, White W, Scully SF (2006) Encapsulation of polyanilines into graphite oxide. Langmuir 22:1729-1734. https ://doi.org/10.1021/la0527339

42. Patel DM, Patel DK, Patel CN (2011) Formulation and evaluation of floating oral in situ gelling system of amoxicillin. ISRN Pharm 2011:1-8. https://doi.org/10.5402/2011/276250

43. Bao H, Li L, Gan LH et al (2010) Thermo-and pH-responsive association behavior of dual hydrophilic graft chitosan terpolymer synthesized via ATRP and click chemistry. Macromolecules 43:5679-5687. https://doi.org/10.1021/ma100894p

44. Baradaran S, Moghaddam E, Basirun WJ et al (2014) Mechanical properties and biomedical applications of a nanotube hydroxyapatite-reduced graphene oxide composite. Carbon N Y 69:32-45. https://doi.org/10.1016/j.carbon.2013.11.054

45. Baradaran S, Moghaddam E, Nasiri-Tabrizi B et al (2015) Characterization of nickel-doped biphasic calcium phosphate/ graphene nanoplatelet composites for biomedical application. Mater Sci Eng C 49:656-668. https://doi.org/10.1016/j. msec.2015.01.050

46. Crisan L, Crisan B, Soritau O et al (2015) In vitro study of biocompatibility of a graphene composite with gold nanoparticles and hydroxyapatite on human osteoblasts. J Appl Toxicol 35:1200-1210. https://doi.org/10.1002/jat.3152

47. Ritger PL, Peppas NA (1987) A simple equation for description of solute release I. Fickian and non-fickian release from nonswellable devices in the form of slabs, spheres, cylinders or discs. J Control Release 5:23-36. https://doi.org/10.1016/01683659(87)90034-4

48. Fan Z, Wang J, Wang Z et al (2013) Casein phosphopeptidebiofunctionalized graphene biocomposite for hydroxyapatite biomimetic mineralization. J Phys Chem C 117:10375-10382. https://doi.org/10.1021/jp312163m

49. Korsmeyer RW, Gurny R, Doelker E et al (1983) Mechanisms of solute release from porous hydrophilic polymers. Int J Pharm 15:25-35. https://doi.org/10.1016/0378-5173(83)90064-9

50. Kopcha M, Lordi NG, Tojo KJ (1991) Evaluation of release from selected thermosoftening vehicles. J Pharm Pharmacol 43:382387. https://doi.org/10.1111/j.2042-7158.1991.tb03493.x

51. Mehrali M, Moghaddam E, Shirazi SFS et al (2014) Mechanical and in vitro biological performance of graphene nanoplatelets reinforced calcium silicate composite. PLoS ONE. https://doi. org/10.1371/journal.pone.0106802

52. Mohandes F, Salavati-Niasari M (2014) Freeze-drying synthesis, characterization and in vitro bioactivity of chitosan/graphene oxide/hydroxyapatite nanocomposite. RSC Adv 4:25993-26001. https://doi.org/10.1039/c4ra03534h

53. Zhong $\mathrm{H}$, Wang L, Fan $\mathrm{Y}$ et al (2011) Mechanical properties and bioactivity of $\beta$-Ca2SiO4ceramics synthesized by spark plasma 
sintering. Ceram Int 37:2459-2465. https://doi.org/10.1016/j. ceramint.2011.03.037

54. Kim HM, Himeno T, Kokubo T, Nakamura T (2005) Process and kinetics of bonelike apatite formation on sintered hydroxyapatite in a simulated body fluid. Biomaterials 26:4366-4373. https ://doi.org/10.1016/j.biomaterials.2004.11.022

55. Belmamouni Y, Bricha M, Essassi EM, El Mabrouk K (2014) Fostering the mechanical strength and biomineralisation of nanohydroxyapatite/multiwall carbon nanotubes (n-HA/MWCNTs) modified silane nanocomposite. J Biomater Tissue Eng 4:349357. https://doi.org/10.1166/jbt.2014.1183

56. Bricha M, Belmamouni Y, Essassi EM et al (2013) Hydrothermal synthesis and appraisal of Mg-doped hydroxyapatite nanopowders. J Biomater Tissue Eng 3:570-580. https://doi.org/10.1166/ jbt.2013.1120
57. Oyefusi A, Olanipekun O, Neelgund GM et al (2014) Hydroxyapatite grafted carbon nanotubes and graphene nanosheets: promising bone implant materials. Spectrochim Acta Part A Mol Biomol Spectrosc. https://doi.org/10.1016/j.saa.2014.04.004

58. Peng $\mathrm{H}$, Meng L, Niu L, Lu Q (2012) Simultaneous reduction and surface functionalization of graphene oxide by natural cellulose with the assistance of the ionic liquid. J Phys Chem C 116:16294-16299. https://doi.org/10.1021/jp3043889

Publisher's Note Springer Nature remains neutral with regard to jurisdictional claims in published maps and institutional affiliations. 